\title{
Perbedaan Prestasi Belajar Mahasiswa Pendidikan IPS FIS UNY
}

\author{
ANIK WIDIASTUTI, SUGIHARYANTO DAN SATRIYO WIBOWO \\ FIS, Universitas Negeri Yogyakarta \\ e-mail: anikwidiastuti@uny.ac.id anin_dyas@yahoo.com
}

\begin{abstract}
Abstrak
Penelitian ini bertujuan untuk mengetahui prestasi belajar mahasiswa Jurusan Pendidikan IPS, FIS, UNY yang meliputi 1) tingginya prestasi belajar mahasiswa, 2) perbedaan prestasi belajar mahasiswa Jurusan Pendidikan IPS, FIS, UNY ditinjau berdasar jenis kelamin, 3) perbedaan prestasi belajar mahasiswa Jurusan Pendidikan IPS, FIS, UNY ditinjau berdasar jalur masuk. Penelitian ini merupakan penelitian deskriptif eksploratif. Populasi penelitian sekaligus menjadi sampel penelitian sebanyak 259 mahasiswa Jurusan Pendidikan IPS, FIS, UNY angkatan 2010 sampai dengan 2012. Teknik pengumpulan data dilakukan dengan menggunakan teknik dokumentasi. Teknik analisis data yang digunakan adalah teknik analisis statistik deskriptif dengan pendekatan kuantitatif.Hasil penelitian menunjukkan bahwa: 1) prestasi belajar mahasiswa Jurusan Pendidikan IPS, FIS, UNY termasuk dalam kategori sangat memuaskan; 2) terdapat perbedaan prestasi belajar mahasiswa Jurusan Pendidikan IPS, FIS, UNY ditinjau berdasar jenis kelamin; 3) terdapat perbedaan prestasi belajar mahasiswa Jurusan Pendidikan IPS, FIS, UNY ditinjau berdasar jalur masuk UNY.
\end{abstract}

Kata kunci: prestasi belajar, IPS

\begin{abstract}
This research aims to know the learning achievement of Social Studies Department students, Faculty of social sciences, Yogyakarta State University which include 1) the high students' achievement, 2) differences in learning achievement of Social Studies Department students, Faculty of social sciences, Yogyakarta State University viewed from the sex, 3) differences in learning achievement of Social Studies Department students, Faculty of social sciences, Yogyakarta State University viewed from the types of entrance tests. This research is a descriptive exploratory research. The population which becomes the research sample includes 259 students of Social Studies Department, Faculty of social sciences, Yogyakarta State University, year of 2010 up to 2012. The data was collected using documentation techniques. The data analysis technique used in this research is descriptive statistical analysis techniques with a quantitative approach. The results show that: 1) the learning achievement of Social Studies Department students, Faculty of social sciences, Yogyakarta State University belongs to the category of excellent; 2) there is a difference regarding the learning achievement of the Social Studies Department students, Faculty of social Sciences, Yogyakarta State University viewed from the aspects of sex; 3) there is a difference regarding the learning achievement of the Social Studies Department students, Faculty of social Sciences, Yogyakarta State University viewed from the kinds of entrance tests.
\end{abstract}

Keywords: learning achievement, Social Studies 


\section{PENDAHULUAN}

Prestasi belajar menjadi salah satu tolok ukur keberhasilan seseorang menempuh kegiatan pendidikan dan keberhasilan proses pembelajaran. Seluruh peserta kegiatan pembelajaran ingin memperoleh prestasi setinggi tingginya sesuai kemampuan yang dimiliki. Prestasi yang baik tentu akan didapat dengan proses belajar yang baik juga. Belajar merupakan proses dari sesuatu yang belum bisa menjadi bisa. Akan tetapi tidak semua peserta kegiatan pembelajaran memperoleh prestasi yang baik. Salah satu prestasi yang diharapkan dapat dicapai pesertanya secara optimal oleh para penyelenggara pendidikan adalah prestasi belajar. Sebagaimana dikemukakan Oemar Hamalik(Soepardjo, 2013: 115) bahwa hasil belajar menunjuk pada prestasi belajar, sedangkan prestasi belajar itu merupakan indikator adanya dan derajat perubahan tingkah laku siswa.

Prestasi adalah hasil dari suatu kegiatan yang telah dikerjakan, diciptakan baik secara individu maupun secara kelompok (Djamarah, 1994: 19). Sedangkan Chomadi (Hidayat \& Suratno: 2010: 13) menyatakan bahwa "prestasi belajar merupakan hasil yang dicapai selama mengikuti pelajaran pada periode tertentu dalam suatu lembaga pendidikan dimana hasil dinyatakan dengan melalui penilaian, yang dapat diwujudkan dalam angka atau simbol". Hal ini sejalan dengan yang disampaikan oleh Ghufron \& Rini Risnawati (2012: 9), prestasi belajar adalah hasil akhir dari aktivitas belajar siswa atau mahasiswa yang dinyatakan dalam bentuk huruf dan angka.

Prestasi belajar dipengaruhi oleh berbagai faktor. Slameto (2010: 54-72) membedakan faktor-faktor yang mempengaruhi prestasi belajar menjadi 2 yaitu faktor internal (faktor dari dalam diri individu) dan faktor eksternal (faktor yang berasal dari luar diri individu). Faktor intern merupakan faktor yang ada dalam diri individu yaitu faktor jasmaniah (kesehatan dan cacat tubuh), faktor psikologis (intelegensi, perhatian, minat, bakat, motif, kematangan, dan kesiapan), dan faktor kelelahan (kelelahan jasmani dan rohani). Faktor ekstern, merupakan faktor yang ada di luar individu, yaitu faktor keluarga (cara orang tua mendidik, relasi anta anggota keluarga, suasana rumah, keadaan ekonomi keluarga, dan latar belakang kebudayaan), faktor sekolah (berkaitan dengan proses pembelajaran, relasi guru dengan siswa, relasi siswa dengan siswa, disiplin sekolah, standar pelajaran di atas ukuran, fasilitas sekolah, metode belajar dan tugas rumah), faktor masyarakat (kegiatan siswa dalam masyarakat, mass media, teman bergaul, bentuk kehidupan masyarakat).

Menurut Tidjan, dkk (2000: 78), faktor yang mempengaruhi prestasi belajar dikelompokkan menjadi dua yaitu:

1. Faktor individu yang belajar, faktor ini meliputi faktor fisiologis dan psikis. Faktor fisiologis meliputi fisiologis permanen (intelegensi yang terbatas, hambatan penglihatan, pendengaran, dan masalah persepsi), fisiologis kontemporer (masalah makanan, kecenderungan, kecapaian). Sedangkan faktor psikis yaitu motif, minat, konsentrasi, intelegensi, dan ingatan.

2. Faktor lingkungan yang dibagi menjadi lingkungan alami (keadaan suhu, kelembaban udara berpengaruh terhadap belajar), lingkungan sosial (harapan orang tua yang tinggi, konflik keluarga, persaingan dan sebagainya) dan faktor materi.

Ekawati dan Wulandari (2011: 19) menyebutkan faktor yang mempengaruhi prestasi belajar adalah faktor biologis (jenis kelamin) dan faktor psikologis (intelegensi, perhatian, minat, bakat, motif, kematangan, dan kesiapan). Oleh karena itu pencapaian prestasi belajar setiap mahasiswa tidaklah sama karena dipengaruhi faktor yang berlainan pula. Berdasar pendapatpendapat ahli di atas, penelitian ini memilih dua faktor yang berpengaruh terhadap prestasi belajar yaitu jenis kelamin dan persaingan (yang dalam hal ini adalah jalur masuk UNY). Prestasi belajar yang dimaksud dalam penelitian ini adalah prestasi belajar mahasiswa yang di- peroleh melalui kegiatan perkuliahan di perguruan tinggi dalam bentuk skor atau angka yang diwujudkan dalam indeks prestasi kumulatif (IPK). 
Walgito menyatakan bahwa prestasi belajar tidak hanya ditentukan oleh ketersediaan sarana prasarana belajar dan kualitas proses pembelajaran saja, tetapi juga ditentukan oleh kualitas peserta yang masuk/input (Muslimin, 2012: 383). Mahasiswa Jurusan Pendidikan Ilmu Pengetahuan Sosial (IPS), Fakultas Ilmu Sosial (FIS), Universitas Negeri Yogyakarta (UNY) berasal dari berbagai latar belakang yang berbeda-beda. Pada kegiatan perkuliahan banyak mahasiswa yang terlibat baik laki-laki maupun perempuan. Hal tersebut menunjukkan adanya perbedaan biologis. Secara umum laki-laki dikarunia fisik yang lebih kuat dibanding perempuan. Perbedaan anatomis biologis dan komposisi kimia dalam tubuh oleh sejumlah ilmuwan dianggap berpengaruh pada perkembangan emosional dan kapasitas intelektual masing-masing. Pendapat ahli dibidang psikologis, Bratanata mengatakan perempuan pada umumnya lebih baik pada ingatan dan laki-laki lebih baik dalam berpikir logis. Oleh karena itu disinyalir terdapat perbedaan prestasi belajar yang dicapai oleh mahasiswa laki-laki dan perempuan (Ekawati \&Wulandari, 2011: 19).

Calon mahasiswa yang menjadi mahasiswa Jurusan Pendidikan IPS diterima melalui jalur yang berbeda-beda pula. Hal ini menunjukkan adanya persaingan para calon mahasiswa. Berbagai bentuk persaingan harus ditempuh para calon mahasiswa untuk diterima di Jurusan Pendidikan IPS, FIS, UNY. Persaingan yang dimaksud dalam penelitian ini adalah dalam bentuk jalur masuk perguruan tinggi. Perguruan Tinggi melakukan beberapa upaya untuk memperoleh calon mahasiswa yang berkualitas yaitu dalam bentuk proses penerimaan mahasiswa atau yang dalam penelitian ini disebut jalur masuk mahasiswa.

Proses penerimaan mahasiswa yang ada dalam lingkup UNY ditempuh melalui beberapa jalur, antara lain PBUD (Penelusuran Bibit Unggul Daerah), Bidik Misi, SNMPTN (Seleksi Nasional Masuk Perguruan Tinggi Negeri), dan SM (Seleksi Mandiri). Mahasiswa PBUD diterima melalui penilaian prestasi belajar yang diperoleh calon mahasiswa pada jenjang pendidikan menengah baik SMA, MA, maupun SMK yang diperhitungkan berdasarkan nilai rapor sejak kelas X sampai dengan kelas XII. Biasanya siswa yang diusulkan oleh sekolah adalah siswa yang telah memiliki prestasi belajar yang baik di sekolahnya. Oleh karena itu ada peran dan andil sekolah dalam penentuan calon mahasiswa yang diusulkan ke perguruan tinggi. Mahasiswa jalur Bidik Misi adalah mahasiswa yang diterima melalui jalur khusus yaitu dengan pertimbangan prestasi belajarnya di sekolah dan kondisi ekonomi keluarga. Mahasiswa Bidik Misi memperoleh beasiswa khusus dengan target dapat lulus dalam waktu maksimal 4 tahun. Mahasiswa SNMPTN adalah mahasiswa yang diterima melalui jalur tes tulis yang diselenggarakan secara nasional, sedangkan mahasiswa Seleksi Mandiri (SM) adalah mahasiswa yang diterima melalui jalur tes mandiri yang dilakukan UNY.

Perbedaan jalur penerimaan mahasiswa ini disinyalir menjadi salah satu penyebab perbedaan prestasi belajar mahasiswa Jurusan Pendidikan IPS, FIS, UNY.

Universitas Negeri Yogyakarta memiliki harapan agar para lulusannya memiliki prestasi belajar yang baik yang ditunjukkan dengan pemerolehan skor Indeks Prestasi (IP) akademik yang tinggi. Dengan IP yang tinggi mahasiswa dapat mengambil SKS yang banyak sehingga dapat mempercepat waktu studi mahasiswa. Selain itu saat melamar kerja, salah satu yang menjadi pertimbangan para penerima kerja adalah Indeks Prestasi Kumulatif (IPK) pelamar kerja. Oleh karena itu, agar mahasiswa lebih memiliki peluang kerja yang tinggi setelah lulus kuliah, diupayakan pencapaian prestasi belajar yang tinggi pula.

Penelitian ini bertujuan untuk mengetahui:

1. prestasi belajar mahasiswa Jurusan Pendidikan IPS FIS, UNY.

2. perbedaan prestasi belajar mahasiswa Jurusan Pendidikan IPS, FIS, UNY ditinjau berdasar jalur penerimaan mahasiswa UNY.

3. perbedaan prestasi belajar mahasiswa Jurusan Pendidikan IPS, FIS, UNY ditinjau berdasar jenis kelamin. 


\section{METODE}

Penelitian ini termasuk penelitian deskriptif eksploratif, karena hanya bertujuan menggambarkan keadaan atau fenomena yang terjadi di lapangan. Deskriptif eksploratif dalam penelitian ini yaitu melukiskan atau menggambarkan perbedaan prestasi belajar mahasiswa Pendidikan IPS, FIS, UNY. Metode yang digunakan dalam penelitian ini adalah metode kuantitatif karena data yang terkumpul berwujud angka-angka dan diolah dengan menggunakan analisis statistik dengan bantuan program SPSS 17 for windows.

Penelitian ini dilakukan di Jurusan Pendidikan Ilmu Pengetahuan Sosial, Fakultas Ilmu Sosial, Universitas Negeri Yogyakarta. Populasi penelitian ini sekaligus sebagai sampel penelitian, yaitu seluruh mahasiswa Jurusan Pendidikan IPS, FIS, UNY angkatan 2010 sampai degan 2012 yang berjumlah 259 mahasiswa.

Pengumpulan data dalam penelitian ini dilakukan dengan dokumentasi. Data yang diperoleh dengan dokumentasi berupa data sekunder dari SIAKAD (Sistem Informasi Akademik) UNY yang diakses melalui admin Jurusan tentang jumlah mahasiswa Pendidikan IPS, FIS, UNY angkatan 2010 sampai dengan 2012 yang aktif kuliah sebanyak 259 mahasiswa. Selain itu diperoleh juga data tentang IPK, jenis kelamin, dan jalur masuk mahasiswa.

Teknik analisis data pada penelitian ini menggunakan statistik deskriptif. Statistik deskriptif digunakan untuk memberikan gambaran setiap variabel dan tabulasi silang (cross tabs)digunakan untuk mengetahui perbedaan prestasi belajar mahasiswa Jurusan Pendidikan IPS, FIS, UNY ditinjau berdasar jalur penerimaan mahasiswa baru UNY dan berdasar jenis kelamin. Cross tabulation dibuat dengan jalan memecah lebih lanjut setiap kesatuan data dalam setiap kategori, menjadi dua atau tiga (atau mungkin lebih) sub kesatuan" (Muslimin, 2002: 130). Setelah itu tabulasi diberi persentase dan dikonsultasikan dengan tolok ukur yang telah ditetapkan. Pengkategorian atau penentuan kriteria prestasi akademik digunakan acuan sesuai peraturan akademik UNY (2006: 24) sebagai berikut:

1.2,00-2,75 : memuaskan

$2.2,76-3,50$ : sangat memuaskan

3.3,51-4,00 : dengan pujian

Penelitian ini menggunakan dua variabel bebas dan satu variabel terikat yaitu meliputi variabel prestasi belajar mahasiswa Jurusan Pendidikan IPS FIS, UNY sebagai variabel terikat (Y) serta jalur penerimaan mahasiswa baru UNY dan jenis kelamin sebagai variabel bebas (X). Data yang diperoleh dari penelitian ini dideskripsikan dengan mentabulasikan data menurut masing-masing variabel. Data yang diperoleh dibuat dalam bentuk tabulasi silang (crosstabs). Tabulasi silang yaitu menyajikan saling berhubungannya variabel yang satu dengan variabel yang lain. Dalam analisis himpunan, keadaan itu disebut denganintersection/irisan himpunan (Suparmoko, 1999: 88). Setelah itu hasil tabulasi diberi persentase dan dikonsultasikan dengan tolok ukur yang telah ditetapkan. Rumus yang dipakai untuk membuat persentase adalah rumus yang dikemukakan oleh Anas Sudijono (2006: 43) sebagai berikut:

$\mathrm{P}=\frac{f}{N} \times 100 \%$

Keterangan: $\quad \mathrm{P}$ : persentase

$\mathrm{f}$ : frekuensi

$\mathrm{N}$ : jumlah responden

Setelah diketahui persentase dilanjutkan analisis data. Analisis perbedaan prestasi belajar mahasiswa Jurusan Pendidikan IPS, FIS, UNY ditinjau dari jalur penerimaan mahasiswa baru dan jenis kelamin dilakukan dengan menggunakan Chi Square (Kai Kuadrat). Adapun teknik perhitungannya sebagai berikut:

1. Menghitung frekuensi yang diharapkan (Sutrisno Hadi, 2004: 385)

$$
F h=\frac{\left(\sum \text { fbaris }-\sum\right. \text { fkolom }}{N}
$$

Keterangan: Fh: frekuensi yang diharapkan $\Sigma$ fbaris : total frekuensi sebaris $\Sigma$ fkolom : total frekuensi sekolom $\mathrm{N} \quad$ : jumlah 
2. Menghitung Kai Kuadrat (Sutrisno Hadi, 2004: 383)

$$
\chi^{2}=\sum \frac{(F o-F h) 2}{F h}
$$

Keterangan: $\quad X^{2}=$ Kai Kuadrat

Fo $=$ Frekuensi Observasi

$\mathrm{Fh}=$ Frekuensi harapan

3. Perbedaan prestasi belajar mahasiswa Jurusan Pendidikan IPS, FIS, UNY ditinjau dari jenis kelamin:

Ho : adalah tidak ada perbedaan prestasi belajar mahasiswa Jurusan Pendidikan IPS, FIS, UNY antara mahasiswa laki-laki dan perempuan. Sedangkan Ha adalah ada perbedaan prestasi belajar mahasiswa Jurusan Pendidikan IPS, FIS, UNY antara mahasiswa laki-laki dan perempuan.

4. Perbedaan prestasi belajar mahasiswa Jurusan Pendidikan IPS, FIS, UNY ditinjau dari jalur penerimaan mahasiswa:

Ho : adalah tidak ada perbedaan prestasi belajar mahasiswa Jurusan Pendidikan IPS, FIS, UNY antara mahasiswa yang diterima dari jalur SNMPTN, PBUD, Bidik Misi, dan seleksi mandiri. Sedangkan Ha adalah ada perbedaan prestasi belajar mahasiswa Jurusan Pendidikan IPS, FIS,
UNY antara mahasiswa yang diterima dari jalur SNMPTN, PBUD, Bidik Misi, dan Seleksi Mandiri (SM).

5. Intepretasi dari perhitungan yang didapat yaitu:

a. Apabila taraf signifikansi lebih besar dari 0,05 maka Ho diterima dan Ha ditolak.

b. Apabila taraf signifikansi lebih kecil dari 0,05 maka Ho dirolak dan Ha diterima.

\section{HASIL DAN PEMBAHASAN}

Sesuai dengan tujuan penelitian, deskripsi responden dibedakan menjadi tiga yaitu deskripsi responden menurut IPK, deskripsi responden menurut jenis kelamin, dan deskripsi responden menurut jalur masuk penerimaan mahasiswa baru UNY. Sampel penelitian ini berjumlah 259 mahasiswa Jurusan Pendidikan IPS, FIS, UNY yang terdiri dari mahasiswa angkatan 2010 sampai dengan mahasiswa angkatan 2012.

\section{Deskripsi Responden Menurut Prestasi Akademik}

Karakteristik responden berdasar pretasi akademik tercermin dalam IPK yang diperoleh mahasiswa selama kuliah. Deskripsi responden menurut IPK dapat dilihat pada tabel 1 berikut:

Tabel 1. Deskripsi Responden Menurut IPK

\begin{tabular}{clrr}
\hline IPK & \multicolumn{1}{c}{ Kategori IPK } & Frekuensi & Persentase \\
\hline $2,00-2,75$ & Memuaskan & 0 & 0,0 \\
\hline $2,76-3,50$ & Sangat Memuaskan & 160 & 61,8 \\
\hline $3,51-4,00$ & Dengan Pujian & 99 & 38,2 \\
\hline & Jumlah & 259 & 100,0 \\
\hline
\end{tabular}

(Sumber: data primer yang sudah diolah, 2013)

Tabel di atas menunjukkan bahwa mahasiswa banyak didominasi oleh mahasiswa yang memiliki IPK dalam kategori sangat memuaskan yaitu berkisar antara 2,76 sampai dengan 3,50. Persentasenya mencapai $62 \%$. Dengan demikian mahasiswa Jurusan Pendi- dikan IPS, FIS, UNY dapat dikatakan memiliki IPK yang baik.

Deskripsi Responden Menurut Jenis Kelamin

Deskripsi responden menurut jenis kelamin dapat dilihat pada tabel 2 berikut: 
Tabel 2.

Deskripsi Responden Menurut Jenis Kelamin

\begin{tabular}{lrr}
\hline \multicolumn{1}{c}{$\begin{array}{c}\text { Jenis } \\
\text { Kelamin }\end{array}$} & Frekuensi & \multicolumn{2}{c}{ Persentase } \\
\hline Laki-laki & 78 & 30,1 \\
Perempuan & 181 & 69,9 \\
Jumlah & 259 & 100 \\
\hline
\end{tabular}

(Sumber: data primer yang sudah diolah, 2013)

Tabel di atas menunjukkan bahwa mahasiswa Jurusan Pendidikan IPS, FIS, UNY angkatan 2010 sampai dangan angkatan 2012 didominasi oleh mahasiswa perempuan yang persentasenya mencapai 70\%. Sementara itu mahasiswa laki-laki hanya mencapai 30\%.

Deskripsi Responden Menurut Jalur Masuk

Deskripsi responden menurut jalur masuk dapat dilihat pada tabel 3 berikut:

Tabel 3.

Deskripsi Responden Menurut Jalur Masuk

\begin{tabular}{lrr}
\hline \multicolumn{1}{c}{ Jalur Masuk } & Frekuensi & Persentase \\
\hline PBUD & 24 & 9,3 \\
Bidik Misi & 36 & 13,9 \\
SNMPTN & 92 & 35,5 \\
Seleksi Mandiri & 107 & 41,3 \\
Jumlah & 259 & 100 \\
\hline
\end{tabular}

(Sumber: data primer yang sudah diolah, 2013)

Tabel 3 di atas menunjukkan bahwa mahasiswa Jurusan Pendidikan IPS, FIS, UNY angkatan 2010 sampai dangan angkatan 2012 didominasi oleh mahasiswa yang diterima melalui jalur masuk seleksi mandiri (SM) yang persentasenya mencapai $41,3 \%$. Sementara itu mahasiswa yang diterima melalui jalur PBUD jumlahnya paling sedikit yaitu hanya mencapai 9,3\%.

1. Prestasi Belajar Mahasiswa Jurusan Pendidikan IPS, FIS, UNY

Penelitian ini hanya berupaya untuk mengetahui seberapa tinggi prestasi belajar mahasiswa Jurusan Pendidikan IPS, FIS, UNY angkatan 2010 sampai dengan 2012. Hasil analisis deskriptif variabel prestasi belajar mahasiswa disajikan pada tabel 4 berikut:

Tabel 4.

\section{Hasil Perhitungan Statistik Deskriptif Prestasi Belajar Mahasiswa}

\begin{tabular}{lr}
\hline \multicolumn{1}{c}{ Statistik } & \multicolumn{1}{r}{ Skor } \\
\hline Jumlah Responden & 259 \\
Rata-rata (Mean) & 3,4534 \\
Median & 3,4700 \\
Modus & 3,47 \\
Standar Deviasi (SD) & 0,10680 \\
Minimum & 2,96 \\
Maksimum & 3,80 \\
\hline
\end{tabular}

(Sumber: data primer yang sudah diolah, 2013)

Berdasarkan tabel di atas dapat diketahui bahwa dari jumlah responden sebanyak 259 mahasiswa memiliki rata-rata prestasi belajar yang ditunjukkan melalui skor IPK sebesar 3,4534; median atau nilai tengahnya sebesar 3,47; modus atau data yang sering muncul yaitu 3,47 denga frekuensi 11. Standar deviasi yang diperoleh adalah sebesar 0,10680; nilai minimum sebesar 2,96 dan nilai maksimum sebesar 3,80.

2. Prestasi Belajar Mahasiswa Jurusan Pendidikan IPS, FIS, UNY Berdasar Jenis Kelamin

Untuk memperoleh data tentang preatasi belajar mahasiswa Pendidikan IPS, FIS, UNY angkatan 2010 sampai dengan 2012 berdasar jenis kelamin dilakukan dengan analisis crosstabs atau tabulasi silang yang dapat dilihat pada tabel di bawah ini: 
Tabel 5. Prestasi Belajar Mahasiswa Berdasar jenis kelamin

\begin{tabular}{|c|c|c|c|c|c|c|c|c|}
\hline \multirow{3}{*}{ Jenis Kelamin } & \multicolumn{6}{|c|}{ Prestasi Belajar } & \multirow{2}{*}{\multicolumn{2}{|c|}{ Jumlah }} \\
\hline & \multicolumn{2}{|c|}{ Memuaskan } & \multicolumn{2}{|c|}{$\begin{array}{c}\text { Sangat } \\
\text { Memuaskan }\end{array}$} & \multicolumn{2}{|c|}{ Dengan Pujian } & & \\
\hline & $\mathrm{f}$ & $\%$ & $\mathrm{f}$ & $\%$ & $\mathrm{f}$ & $\%$ & $\mathrm{f}$ & $\%$ \\
\hline Laki-laki & 0 & 0,00 & 57 & 22,01 & 21 & 8,11 & 78 & 30,12 \\
\hline Perempuan & 0 & 0,00 & 103 & 39,77 & 78 & 30,11 & 181 & 69,88 \\
\hline Jumlah & 0 & 0,00 & 160 & 61,78 & 99 & 38,22 & 259 & 100,00 \\
\hline
\end{tabular}

(Sumber: data primer yang sudah diolah, 2013)

Berdasarkan tabel 5 yang dianalisis dengan perhitungan persentase secara total dari seluruh responden, dapat diketahui bahwa sebagian besar respoden laki-laki memiliki prestasi belajar pada kategori sangat memuaskan yaitu sebanyak 57 mahasiswa atau sebesar 22,01\%. Begitu juga dengan responden perempuan, sebagian besar mahasiswa memiliki prestasi belajar pada kategori sangat memuaskan yaitu sebanyak 103 mahasiswa atau sebesar 39,77\%. Responden laki-laki dan perempuan tidak ada yang memiliki prestasi belajar yang termasuk pada kategori memuaskan.

Untuk mengetahui ada tidaknya perbedaan prestasi belajar antara mahasiswa laki-laki dan perempuan berdasarkan analisis statistik, dilakukan uji beda dengan Chi Square yang hasilnya dapat dilihat pada tabel 6 .

Tabel 6 Chi Square Test

\begin{tabular}{lrrrr}
\hline & Value & df & & Asymp. Sig. (2-sided) \\
\hline Pearson Chi-Square & $6.036^{\mathrm{a}}$ & 1 & .014 \\
Likelihood Ratio & 6.224 & 1 & .013 \\
N of Valid Cases & 259 & & & \\
\hline
\end{tabular}

Dari hasil analisis Chi Square di atas, perhitungan uji beda signifikansi sebesar 0,014 . Hasil tersebut menunjukkan bahwa nilai signifikansi yang diperoleh lebih kecil dari nilai signifikansi yang telah ditetapkan sebesar 0,05 maka Ho ditolak dan Ha diterima, se- hingga dapat disimpulkan ada perbedaan prestasi belajar mahasiswa laki-laki dan perempuan Jurusan Pendidikan IPS, FIS, UNY.

Prestasi belajar mahasiswa berdasar jenis kelamin di atas juga dapat dianalisis secara sendiri-sendiri seperti pada tabel 7 berikut:

Tabel 7. Persentase prestasi belajar mahasiswa berdasar jenis kelamin secara sendiri-sendiri.

\begin{tabular}{|c|c|c|c|c|c|c|c|c|}
\hline \multirow{3}{*}{ Jenis Kelamin } & \multicolumn{6}{|c|}{ Prestasi Belajar } & \multirow{2}{*}{\multicolumn{2}{|c|}{ Jumlah }} \\
\hline & \multicolumn{2}{|c|}{ Memuaskan } & \multicolumn{2}{|c|}{$\begin{array}{c}\text { Sangat } \\
\text { Memuaskan }\end{array}$} & \multicolumn{2}{|c|}{$\begin{array}{c}\text { Dengan } \\
\text { Pujian }\end{array}$} & & \\
\hline & $\mathrm{f}$ & $\%$ & $\mathrm{f}$ & $\%$ & $\mathrm{f}$ & $\%$ & $\mathrm{f}$ & $\%$ \\
\hline Laki-laki & 0 & 0,00 & 57 & 73,08 & 21 & 26,92 & 78 & 100,00 \\
\hline Perempuan & 0 & 0,00 & 103 & 56,91 & 78 & 43,09 & 181 & 100,00 \\
\hline
\end{tabular}

(Sumber: data primer yang sudah diolah, 2013) 
Tabel 7 di atas menunjukkan bahwa dari 78 responden laki-laki terdapat 57 mahasiswa atau sebanyak $73,08 \%$ memiliki prestasi belajar dalam kategori sangat memuaskan, 21 mahasiswa atau sebesar 26,92\% memiliki prestasi belajar dalam kategori dengan pujian. Responden perempuan berjumlah 181 mahasiswa yaitu sebanyak 103 mahasiswa atau sebesar $56,91 \%$ memiliki prestasi belajar dalam kategori sangat memuaskan dan 78 mahasiswa atau sebesar $43,09 \%$ termasuk dalam kategori dengan pujian.

Rata-rata prestasi belajar mahasiswa Jurusan Pendidikan IPS, FIS, UNY Berdasar Jenis Kelamin dapat dilihat pada tabel 8 berikut:

Prestasi belajar mahasiswa laki-laki memiliki rata-rata lebih tinggi daripada mahasiswa perempuan. Walaupun perbedaan skor rata-rata tersebut tidak terlalu signifikan hanya sebesar 0,07 akan tetapi hal ini menunjukkan adanya perbedaan prestasi be- lajar antara mahasiswa laki-laki dan perempuan.

Tabel 8

Rata-rata Prestasi Belajar Berdasar Jenis Kelamin

\begin{tabular}{rr}
\hline Jenis Kelamin & Prestasi Belajar \\
\hline Laki-laki & 3,473704 \\
Perempuan & 3,403924 \\
\hline
\end{tabular}

(Sumber: data primer yang sudah diolah, 2013)

3. Prestasi Belajar Mahasiswa Pendidikan IPS, FIS, UNY Berdasar Jalur Masuk UNY

Untuk memperoleh data tentang preatasi belajar mahasiswa Pendidikan IPS, FIS, UNY angkatan 2010 sampai dengan 2012 berdasar jalur masuk UNY dilakukan dengan analisis crosstabs atau tabulasi silang yang dapat dilihat pada table 9 berikut:

Tabel 9. Prestasi Belajar Mahasiswa Berdasar Jalur Masuk

\begin{tabular}{|c|c|c|c|c|c|c|c|c|}
\hline \multirow{3}{*}{ Jalur Masuk } & \multicolumn{6}{|c|}{ Prestasi Belajar } & \multirow{2}{*}{\multicolumn{2}{|c|}{ Jumlah }} \\
\hline & \multicolumn{2}{|c|}{ Memuaskan } & \multicolumn{2}{|c|}{$\begin{array}{c}\text { Sangat } \\
\text { Memuaskan }\end{array}$} & \multicolumn{2}{|c|}{ Dengan Pujian } & & \\
\hline & $\mathrm{F}$ & $\%$ & $\mathrm{~F}$ & $\%$ & $\mathrm{~F}$ & $\%$ & $\mathrm{~F}$ & $\%$ \\
\hline PBUD & 0 & 0,00 & 15 & 5,79 & 9 & 3,48 & 24 & 9,27 \\
\hline Bidik Misi & 0 & 0,00 & 15 & 5,79 & 21 & 8,11 & 36 & 13,90 \\
\hline SNMPTN & 0 & 0,00 & 46 & 17,76 & 46 & 17,76 & 92 & 35,52 \\
\hline SM & 0 & 0,00 & 84 & 32,43 & 23 & 8,88 & 107 & 41,31 \\
\hline Jumlah & 0 & 0,00 & 160 & 61,78 & 99 & 38,22 & 259 & 100,00 \\
\hline
\end{tabular}

(Sumber: data primer yang sudah diolah, 2013)

Berdasarkan tabel 9 yang dianalisis dengan perhitungan persentase secara total dari seluruh responden, dapat diketahui bahwa sebagian besar respoden yang masuk di Jurusan Pendidikan IPS, FIS, UNY melalui jalur PBUD memiliki prestasi belajar pada kategori sangat memuaskan yaitu sebanyak 15 mahasiswa atau sebesar 5,79\%. Mahasiswa yang diterima melalui jalur Bidik Misi sebagian besar memiliki prestasi belajar pada ka- tegori dengan pujian yaitu sebanyak $8,11 \%$, sedangkan jumlah mahasiswa yang diterima melalui jalur SNMPTN memiliki prestasi belajar dalam kategori sangat memuaskan dan dengan pujian yaitu sebanyak 46 mahasiswa atau sebesar $17,76 \%$. Responden yang diterima melalui jalur masuk SM (Seleksi Mandiri), sebagian besar mahasiswa memiliki prestasi belajar pada kategori sangat memuaskan yaitu sebanyak 84 mahasiswa atau sebesar 
32,43\%. Responden yang diterima malalui jalur PBUD, Bidik Misi, SNMPTN, SM tidak ada yang memiliki prestasi belajar yang termasuk pada kategori memuaskan.

Untuk mengetahui ada tidaknya perbedaan prestasi belajar antara mahasiswa yang di- terima melalui jalur masuk PBUD, Bidik Misi, SNMPTN, dan SM berdasarkan analisis statistik, dilakukan uji beda dengan Chi Square yang hasilnya dapat dilihat pada tabel 10.

Tabel 10 Chi-Square Tests

\begin{tabular}{lrrrr}
\hline & Value & df & Asymp. Sig. (2-sided) \\
\hline Pearson Chi-Square & $24.254^{\mathrm{a}}$ & 3 & .000 \\
Likelihood Ratio & 24.976 & 3 & .000 \\
N of Valid Cases & 259 & & \\
\hline
\end{tabular}

a. 0 cells $(.0 \%)$ have expected count less than 5 . The minimum expected count is 9.17.

Dari hasil analisis Chi Square di atas, perhitungan ujibeda signifikansi sebesar 0,000. Hasil tersebut menunjukkan bahwa nilai signifikansi yang diperoleh lebih kecil dari nilai signifikansi yang telah ditetapkan sebesar 0,05 maka Ho ditolak dan Ha diterima, sehingga dapat disimpulkan ada perbedaan prestasi belajar mahasiswa Jurusan Pendidikan IPS, FIS, UNY yang diterima melalui jalur masuk PBUD, Bidik Misi, SNMPTN dan SM.

Prestasi belajar mahasiswa berdasar jalur masuk di atas juga dapat dianalisis secara sendiri-sendiri seperti pada tabel 11 berikut:

Tabel 11. Persentase Prestasi Belajar Mahasiswa Berdasar Jalur Masuk Secara Sendiri-sendiri.

\begin{tabular}{|c|c|c|c|c|c|c|c|c|c|}
\hline \multirow{3}{*}{ Jalur Masuk } & \multicolumn{7}{|c|}{ Prestasi Belajar } & \multirow{2}{*}{\multicolumn{2}{|c|}{ Jumlah }} \\
\hline & \multicolumn{3}{|c|}{ Memuaskan } & \multicolumn{2}{|c|}{$\begin{array}{c}\text { Sangat } \\
\text { Memuaskan }\end{array}$} & \multicolumn{2}{|c|}{ Dengan Pujian } & & \\
\hline & $\mathrm{f}$ & & $\%$ & $\mathrm{f}$ & $\%$ & $\mathrm{f}$ & $\%$ & $\mathrm{f}$ & $\%$ \\
\hline PBUD & & 0 & 0,00 & 15 & 62,50 & 9 & 37,50 & 24 & 100,00 \\
\hline Bidik Misi & & 0 & 0,00 & 15 & 41,67 & 21 & 58,33 & 36 & 100,00 \\
\hline SNMPTN & & 0 & 0,00 & 46 & 50,00 & 46 & 50,00 & 92 & 100,00 \\
\hline SM & & 0 & 0,00 & 84 & 78,51 & 23 & 21,49 & 107 & 100,00 \\
\hline
\end{tabular}

(Sumber: data primer yang sudah diolah, 2013)

Tabel di atas menunjukkan bahwa dari 24 responden yang diterima melalui jalur masuk PBUD terdapat 15 mahasiswa atau sebanyak $62,50 \%$ memiliki prestasi belajar dalam kategori sangat memuaskan, 9 mahasiswa atau sebesar $37,50 \%$ memiliki prestasi belajar dalam kategori dengan pujian. Responden yang diterima melalui jalur Bidik Misi berjumlah 36 mahasiswa yaitu sebanyak
15 mahasiswa atau sebesar 41,67\% memiliki prestasi belajar dalam kategori sangat memuaskan dan 21 mahasiswa atau sebesar 58,33\% termasuk dalam kategori dengan pujian. Responden yang diterima melalui jalur SNMPT berjumlah 96 mahasiswa yaitu sebanyak 46 mahasiswa atau sebesar 50,00\% memiliki prestasi akademik dalam kategori sangat memuaskan dan sisanya sebanyak 46 
mahasiswa atau sebesar $50,00 \%$ termasuk dalam kategori dengan pujian. Sedangkan responden yang diterima melalui jalur SM berjumlah 107 mahasiswa yaitu sebanyak 84 mahasiswa atau sebesar memiliki prestasi akademik dalam kategori sangat memuaskan, dan 23 mahasiswa atau sebesar termasuk dalam kategori dengan pujian.

Prestasi belajar berdasar jalur masuk rata-ratanya dapat dilihat pada tabel 12 berikut:

\section{Tabel 12. Rata-rata Prestasi Belajar Berdasar Jalur Masuk}

\begin{tabular}{lr}
\hline \multicolumn{1}{c}{ Jalur Masuk } & Rata-rata IPK \\
\hline PBUD & 3,4933 \\
Bidik Misi & 3,4861 \\
SNMPTN & 3,4868 \\
Seleksi Mandiri (SM) & 3,4047 \\
\hline
\end{tabular}

(Sumber: data primer yang sudah diolah, 2013)

Tabel 12 menunjukkan bahwa rata-rata prestasi belajar mahasiswa Jurusan Pendidikan IPS, FIS, UNY yang paling tinggi diperoleh mahasiswa yang diterima melalui jalur masuk PBUD yaitu sebesar 3,4933, sedangkan rata-rata prestasi belajar yang paling rendah diperoleh mahasiswa yang diterima melalui jalur Seleksi Mandiri (SM).

\section{SIMPULAN}

Berdasarkan hasil penelitian dan pembahasan yang telah diuraikan maka dapat ditarik kesimpulan sebagai berikut:

1. Prestasi belajar mahasiswa Jurusan Pendidikan IPS, FIS, UNY termasuk dalam kategori sangat memuaskan. Hal ini ditunjukkan dalam hasil penelitian yang menyatakan bahwa $61,8 \%$ dari responden memiliki prestasi belajar sangat memuaskan.

2. Terdapat perbedaan prestasi belajar mahasiswa Jurusan Pendidikan IPS, FIS, UNY antara mahasiswa laki-laki dan perempuan.

3. Terdapat perbedaan prestasi belajar ma- hasiswa Jurusan Pendidikan IPS, FIS, UNY antara mahasiswa yang diterima melalui jalur PBUD, Bidik Misi, SNMPTN, dan Seleksi Mandiri (SM).

Dalam rangka memberikan alternatif pemecahan terhadap prestasi belajar mahasiswa Jurusan Pendidikan IPS, FIS, UNY terdapat beberapa hal yang perlu dilakukan antara lain:

1. Mahasiswa yang diterima melalui jalur PBUD dan Bidik Misi hendaknya dapat meningkatkan dan mempertahankan prestasinya karena diterima melalui jalur khusus (nontes) yaitu berdasar prestasi sebelumnya saat duduk di bangku sekolah menengah.

2. Mahasiswa yang diterima melalui jalur Seleksi Mandiri (SM) hendaknya dapat berkompetisi dengan mahasiswa yang diterima melalui jalur lain dengan meningkatkan ketekunannya dalam mengikuti perkuliahan.

3. Jurusan P. IPS hendaknya memprioritaskan penerimaan mahasiswa yang diterima melalui jalur Bidik Misi dikarenakan memiliki prestasi yang lebih baik dibandingkan mahasiswa yang diterima melalui jalur lain.

4. Perguruan tinggi hendaknya mempertimbangkan jalur penerimaan Seleksi Mandiridikarenakan prestasinya paling rendah dan tidak seoptimal mahasiswa yang diterima melalui jalur lainnya.

\section{UCAPAN TERIMA KASIH}

Atas terlaksananya penelitian ini, kami mengucapkan terimakasih kepada :

1. Dekan FIS UNY, Prof. Dr. Ajat Sudrajat, M.Ag. yang telah memberikan fasilitas berupa ijin pelaksanaan penelitian.

2. Bapak/ibu dosen Jurusan Pendidikan IPS, FIS, UNY yang telah memberikan bantuan pikiran dan masukan untuk kebaikan penelitian ini.

3. Admin Jurusan Pendidikan IPS, FIS, UNY yang telah membantu pengumpulan data penelitian. 


\section{DAFTAR PUSTAKA}

Anonim.2006. Peraturan Akademik Universitas Negeri Yogyakarta. Yogyakarta: UNY Press.

Djamarah, Syaiful Bahri. 1994. Prestasi Belajar dan Kompetensi Guru. Surabaya: Usaha Nasional.

Ekawati, Aminah\& Shinta Wulandari.2011. Perbedaan Jenis Kelamin terhadap Kemampuan Siswa dalam MataPelajaran Matematika (Studi Kasus Sekolah Dasar). Socioscientia. Jurnal Ilmu-ilmu Sosial. Diakses dari http:// www. kopertis.net journal pada hari Jumat tanggal 11 Oktober 2013 pukul 13.10 WIB.

Hadi, Sutrisno. 2004. Metedologi Research. Yogyakarta: Andi Offset.

Hidayat, Herman \& Kartono Sukarto. 2010. Pengaruh Minat Belajar Siswa Terhadap Prestasi Belajar Mata Diklat PDTM. Jurnal Pendidikan Teknik Mesin. Vol. 12 No. 1, Juni 2010. Versi Elektronik. Diakses dari http: www. journal.unness.ac.id pada hari Senin tanggal 1 April 2013 pukul 12.30 WIB.
Muslimin. 2002. Metode Penelitian di Bidang Sosial. Malang: UMM Press.

Muslimin, Zidni Imawan. (2012). Prestasi Belajar Mahasiswa Ditinjau dari Jalur Penerimaan Mahasiswa Baru, Asal Sekolah, dan Tes Potensi Akademik.Jurnal Penelitian Psikologi Vol 03 No. 01.Versi Elektronik. hal 108-126.

Slameto. 2010. Belajar dan Faktor-faktor yang Mempengaruhinya. Jakarta: Rineka Cipta.

Soepardjo. 2013. Kontribusi Status Sosial Ekonomi Keluarga dan Sikap Kebangsaan terhadap Prestasi Belajar Sejarah. Jurnal Penelitian dan Evaluasi Pendidikan Vol 17. No. 01.Versi elektronik.

Sudijono, Anas. 2006. Pengantar Statistik Pendidikan. Jakarta: PT Raja Grafindo Persada.

Suparmoko. 1999. Metode Penelitian Praktis. Yogyakarta: BPFE.

Tidjan, et al. (2000). Bimbingan dan Konseling untuk Sekolah. Yogyakarta: UPP-UNY 